\title{
A FUNDAÇÃO DE UM ESTADO: CIDADE DE SÃO SALVADOR, BRASIL
}

\author{
ENI PUCCINELLI ORLANDI ${ }^{1}$
}

\begin{abstract}
RESUMO: Analisamos o texto de fundação da cidade de São Salvador: o Regimento outorgado por D. João III a Tomé de Souza, datado de 17 de dezembro de 1548. Nosso objetivo é, pensando a força simbólica e política da cidade na sociedade ocidental, refletir sobre a relação da fundação da cidade de São Salvador, a primeira cidade do Brasil, que já nasce cidade, com a colonização. Uma cidade que é uma fortaleza que é uma capital. Capital que instala o governo português no território brasileiro. Fundação de uma cidade, afirmação de um Estado (Portugal/Brasil), que tinge de sentidos dúbios o que virá a ser o Brasil, abrindo desse modo as portas da história a um processo de significação trabalhado por sutilezas, por ambigüidades, pelo equívoco, pela constituição de sentidos que não são Um.
\end{abstract}

Palavras-chave: fundação, colonização, cidade.

ABSTRACT: In this paper, we analyze the founding text of the city of São Salvador: the "Regimento" given by D. João III to Tomé de Souza, dated December 17, 1548. Our goal was to think over on the relationship between the foundation of the city of São Salvador, the first city in Brazil (and which has been born as a city), with colonization, considering the political and symbolic force of a city in Western society. A city that is a fortress that is the capital. A capital that installs the Portuguese government in Brazilian territory. Foundation of a city, an affirmation of the State (Portugal / Brazil), that imbues of dubious senses what will be Brazil, thus opening the doors of history to a process of signification worked by subtleties, by ambiguity, by equivocity, by the constitution of meanings that are not One.

Keywords: foundation, colonisation, city.

\section{INTRODUÇÃO}

Nosso objeto de análise é o texto da fundação - um Regimento - de São Salvador, outorgado por D. João III a Tomé de Souza. Datado de 17 de dezembro de 1548, é o documento mais importante do século XVI. Nosso objetivo inicial é o de mostrar que ao fundar São Salvador, não estava o rei fundando uma cidade mas um Estado, o Brasil, e, ao mesmo tempo, instalando um governo de Portugal no Brasil, dando início à colonização. Ao mesmo tempo chamamos a atenção para o fato de que a noção de espaço conta na concepção de Estado, nesse caso, o espaço urbano em que estará simbolizado o poder sobre todo o espaço (geografia política).

Como é uma situação particular, esta de falar de uma cidade que representa um Estado, que nasce, no entanto, já submetido a outro, vamos fazer uma rápida passagem pela questão da noção de Estado.

\footnotetext{
${ }^{1}$ Univás/Unicamp (Labeurb). enip@uol.com.br
} 
Se pensarmos a etimologia da palavra Estado, ela está ligada - e isto nos interessa no caso de São Salvador - ao grego "polis" (cidade). De polis advém o sentido de político que é a ciência de governar a cidade (cidade-estado, para os gregos). Para os romanos, a civitas ou res publica é chamada de status. Deixando a etimologia que, para nós, aqui, nos serve para mostrar a ligação ancestral de Estado e cidade (para os gregos), e como coisa pública (para os romanos), o Estado é entendido modernamente, de forma geral, como organização jurídico-política de uma sociedade para realizar o bem público, com governo próprio e território determinado. Mas podemos retomar o que pensa Maquiavel (1969) ao colocar a noção de Estado na perspectiva da segurança nacional: segundo Maquiavel, o Estado Real é pensado da forma como ele de fato é, ou seja, como incapaz de estabelecer a ordem de modo perfeito, embora consiga evitar e amenizar o caos e a barbárie. O Estado é, então, para ele, pautado em força e poder que, juntos, podem produzir a ordem necessária a ele (a segurança nacional). E este é um sentido que estará sempre presente nesta noção. Para Durkheim (2002), o Estado é a instituição da disciplina moral que vai orientar a conduta do homem. E a política é a relação entre governantes e governados. Já em Weber (1991) encontramos uma formulação bem explícita de Estado ligada a coerção: o Estado é uma instituição política que, dirigida por um governo soberano, detém o monopólio da força física, em determinado território, subordinando a sociedade em que nele vive (grifo nosso). Além de possuir o monopólio da força, dos meios de violência, o Estado deve garantir a manutenção das leis, da ordem e da estabilidade nacional. Com a revolução francesa, temos o Estado-nação em que se associa a noção de nação a ideais de igualdade e liberdade. Essa noção de Estado-nação tem hoje, na política internacional, grande destaque $^{2}$. Mas não é a única forma de conceber o Estado. Desses desenvolvimentos todos dessa noção de Estado resulta que hoje se pensa o Estado como uma instituição organizada politicamente, socialmente e juridicamente, ocupando um território ${ }^{3}$ definido, normalmente onde a lei máxima é uma constituição escrita, e dirigida por um governo que possui soberania reconhecida tanto interna como externamente. Um Estado soberano é sintetizado pela máxima “Um governo, um povo, um território". Máxima que, em todos seus componentes, é sujeita a polêmica, contradição e equívoco. Pensando-se a relação com a sociedade, o Estado é responsável pela organização e o controle social, pois detém, segundo Weber, o monopólio legítimo do uso da força (coerção, especialmente a legal).

Voltando ao nosso Regimento - que ordena a fundação da cidade de São Salvador trata-se de um gesto fundador em sua espessura semântico-discursiva na formação do Brasil: fundação de uma cidade, afirmação de um Estado (Portugal/Brasil), marco forte de um nosso início jurídicamente atestado, politicamente significado e que tinge de sentidos dúbios o que virá a ser o Brasil na conjunção produzida entre cidade, estado, colonização, que abrirá as portas da história a um processo de significação trabalhado pela ambigüidade, pelo equívoco, pela constituição sorrateira de sentidos que não são Um.

${ }^{2}$ Interessa observar que a noção de Estado-nação, que é tão destacada por organismos internacionais na contemporaneidade, traz, com ela, a ideia de um território delimitado composto de um governo e uma população de composição étnico-cultural coesa. Isto, como podemos ver, não é sem polêmica em um mundo em que os movimentos migratórias e as histórias políticas são tão conturbadas como hoje.

${ }^{3}$ Sobre a questão de território cf. E. Orlandi(2011). 
Lembrando o que diz a escritora nigeriana Adichie, em seu "Uma única história rouba das pessoas a sua dignidade", onde ela critica sobretudo o "autêntico", o "preconceito", fazendo a crítica da história única ${ }^{4}$, eu diria que, neste nosso caso, o da fundação de São Salvador, pensar uma história única tira a complexidade de nossa história, de nossas histórias. Em uma história, há muitas e, portanto, há sentidos que não confinam mas que partem em muitas e variadas direções. Não são diferentes versões de uma história: são os diferentes sentidos de muitas histórias possíveis. Relacionar-se pois com um acontecimento - como o do Regimento e a fundação de São Salvador - é relacionar-se com muitas, múltiplas histórias. Este é o caminho que tomamos aqui.

No caso de nossa análise, estamos no século XVI, e estamos tratando de um Regimento feito por um Rei, o rei de Portugal, na colonização do Brasil. Essas são as condições de produção em sentido estrito e amplo.

É o momento do surgimento da noção de Estado que temos hoje, mas está longe de ser a que praticamos em nossa contemporaneidade. Naquele momento, começa a haver, diferentemente da época medieval, uma identificação dos indivíduos com a figura do rei e uma transferência, para ele, da fidelidade que antes estava focada nas cidades e nos senhores feudais. O rei torna-se o senhor absoluto do território nacional e estabelece todo o aparato administrativo, incluindo o monopólio da força e dos meios de coerção física. É o Estado absolutista em que o rei personifica o Estado.

Estamos em uma situação singular, contraditória: a criação em outro território (que não Portugal) de uma cidade que se sobredetermina como Estado. Mas um Estado aqui submetido ao Rei lá. Isto é a particularidade da colonização. De outro ponto de vista, o de Portugal, seria o mesmo Estado, o português, aqui. Mas seria outro território. Como vemos, quando se trata de colonização, essas noções são opacas, equívocas e trazem muito a refletir. Não poderíamos, em uma posição de uma história única e linear, falar em Estado, referindonos ao Brasil, daquele momento nascente, já que não é soberano. Mas ainda assim, a cidade de São Salvador não é só uma cidade. E no vão dos sentidos, podemos sim pensar a questão do Estado posta para o Brasil, neste início da colonização. Eles estão construindo um Estado para eles, Estado que será o nosso. Com a Independência. O que afinal está ali significando e significado de Brasil na fundação de São Salvador?

De todo modo, para um país, um Estado, uma nação, não basta existir. É preciso ser dito como existente em um discurso que, pelo fato mesmo de dizer, o/a institui. E quem o diz tem de estar em posição-sujeito capaz de realizar este gesto de fundação, além de prescrever as condições da fundação. São ordens.

Este é um caso especial do que Pêcheux chama de Língua de Estado. Já tivemos ocasião de trabalhar com ela em outra circunstância de enunciação (2009) - a da propaganda política. Neste caso presente é outro seu funcionamento. Oficial, institucional, carregado do peso de uma história a se fazer: a da criação do Estado Brasil. Um país submetido a outro (presentificando, no entanto, os germens de sua futura soberania). Mas este é o traço sempre sujeito a equívoco da colonização: o da submissão de um país/Estado a outro,

${ }^{4}$ Participo de um Gt Internacional de promoção do multilinguismo (presidido por B. Cerquiglini) e são muitas as reflexões que temos feito a propósito da língua única (o inglês?) e a necessidade de praticar o multilinguismo como forma de estar no movimento das histórias e dos sentidos possíveis e plurais. 
senão, seria mera extensão territorial. Vejamos, portanto, o nascimento do Brasil como Estado em sua pompa e circunstância. Circunstância que o traciona submetido a outro Estado, Portugal.

O Regimento é um instrumento jurídico-administrativo. Mas há algo a mais: é a palavra do Rei. Portanto um instrumento político. Fundação de uma fortaleza, fundação de uma cidade. Governo de um país. Manifestação de um Estado. São muitos os sentidos aí investidos. Polissemia.

Não significa que, antes, desde 1530, com as capitanias e os donatários, já não houvesse a presença portuguesa no Brasil. Mas não fazia um sistema político organizado. Não constituía um aparato administrativo aqui instalado que representasse um governo e garantisse formalmente segurança aos seus habitantes ${ }^{5}$. Eles se dispersavam em suas individualidades e aventuras por um espaço ainda não sistematicamente governado, administrado em todas suas letras. Havia ocupação, havia povoamento iniciante mas não havia se instalado propriamente a colonização com seu aparato jurídico-político (que, para se instalar, precisa de uma cidade, de uma capital). É o sentido mesmo de colonização que me estimula na feitura deste estudo ${ }^{6}$.

Sabemos que, no início, Portugal não se interessou pela ocupação do Brasil já que seu interesse maior estava no Oriente, voltado para o comércio com especiarias. A partir de 1516, D. Manuel manda distribuir machados e enxadas aos portugueses dispostos a povoar o Brasil, começando assim a ocupação, mas em 1518 os índios acabam com a colônia em Porto Seguro, atacando a Igreja e a Feitoria.

Na realidade, Portugal enviou apenas algumas expedições que aqui instalaram feitorias para a exploração do pau Brasil. As feitorias não se sustentavam pois, como vimos, eram atacadas frequentemente. A região onde vai ser fundada São Salvador já era habitada desde 1510, dado um naufrágio de um navio francês. Os dois personagens de destaque desta fase, anterior à fundação da cidade, são Diogo Álvares Correia (Caramuru e a fundação da capela em louvor a Nossa Senhora da Graça, em 1534), que viveu na Bahia, e João Ramalho, que se instalou na região de São Vicente. Há outro personagem, Francisco Pereira Coutinho, donatário, que recebeu capitania hereditária na Bahia, na região da ladeira da Barra. Mas segundo se conta, este, arrogante e cruel, foi devorado pelos índios em ritual antropofágico.

Portanto, podemos tomar a chegada de Tomé de Souza, pela Ponta do Padrão, em 29 de março de 1549, como a primeira tentativa de governo, o primeiro gesto efetivo de ocupação, povoamento, defesa e mando, logo de colonização do Brasil, feita por D. João

${ }^{5}$ Falar em segurança da população é bastante ambíguo. De que população? No entanto, um dos componentes decisivos dessa fundação é a representação da segurança pelo estabelecimento de uma fortaleza.

${ }^{6}$ Talvez mereça referência, o caso de Esparta e Atenas, mais particularmente. Estas são cidade-estados, mas muito diferentes de São Salvador. O que nos interessa aqui lembrar é que no caso de Esparta, por exemplo, a fundação não se explica por processo invasionista. Houve o desaparecimento da economia de palácio e sua substituição pela economia natural baseada em recursos locais: há o deslocamento dos centros de força dos palácios para as áreas de planície. Já Atenas se liga mais ao desenvolvimento mercantil. A população de Esparta é um núcleo de cidadãos que detém exclusividade de direitos de atuação política; já em Atenas, a população tem direitos civis sem direitos políticos. São diferenças muito importantes e com consequiências fortes sobre a história econômica e política dessas cidades. Por isso, a questão da colonização, em nosso caso, é determinante. É ela que dá sentido ao que é a fundação de uma cidade, como São Salvador, que representa um Estado, como veremos. 
III, ordenando a fundação de uma cidade. São Salvador já nasce cidade, capital ${ }^{7}$. É uma cidade-fortaleza. Ponta de lança da colonização. Tinha a força do gesto colonizador porque representava não apenas a ocupação, mas a presença permanente, a defesa do território, a vinculação com a Coroa. Nunca foi província ou vila, pois nasce cidade e foi durante muito tempo conhecida como a maior cidade das Américas. Em 1572 o governo colonial dividiu o país em dois governos, um em São Salvador e outro no Rio de Janeiro, mas em 1581 o governo voltou a ter seu locus próprio só em São Salvador. Mais tarde, em 1763, a capital muda definitivamente para o Rio de Janeiro. Até 1763 a cidade de São Salvador da Bahia de Todos os Santos foi a capital, a sede da administração colonial do Brasil.

Sem dúvida, um dos pontos fortes da ação colonizadora realizada em e por São Salvador se deve ao fato de que fica também administrado o fator econômico por excelência que está se instalando: o cultivo da cana-de-açúcar que aí se faz e se estende para Pernambuco. Foi por causa da economia centrada no comércio dos engenhos instalados no Recôncavo que uma grande população de europeus, índios, negros e mestiços aí se instalou. Regidos pela capital. Mais tarde, com a república e o enfraquecimento do cultivo do açúcar, São Salvador perde sua importância e poder. Deriva.

Como dissemos, interessa-nos compreender o sentido e o modo de funcionamento da colonização. Colonização é definida como o nome do processo de povoamento, exploração e dominação, em nosso caso, de um país por outro. Mas é preciso mais: uma cidade fortaleza, bem situada, que organiza o território. Instituição e, ao mesmo tempo, submissão de um Estado a outro. Somos também alertados que não devemos confundir a colonização do Brasil e a época do Brasil Colônia, pois não coincidem: o processo de povoar, desenvolver o território começa antes e vem até mesmo antes da ocupação portuguesa (pelos índios) e vai até depois (pelos imigrantes). Portanto temos algumas palavras chave cujos sentidos devemos compreender: ocupação, povoamento, exploração, dominação, desenvolvimento do território. Colonização. Ficaremos atentos a elas. Nuances dos processos de significação.

\section{O REGIMENTO: UM INSTRUMENTO JURÍDICO-POLÍTICO ADMINISTRATIVO}

No funcionamento do que Pêcheux chama de Língua de Estado, um instrumento jurídico-político como um Regimento tem uma força de realidade pujante e eficaz. A Língua de Estado, segundo a definição de Pêcheux (2011) "tende a passar pelo real, a representálo sem distância, a constituir seu equivalente: o dizível e o existente devem coincidir sem falha nos enunciados performativos, pronto para que a falha retorne pelo viés do absurdo".

Como não podemos deixar de observar, as condições em que funciona a Língua de Estado é extremamente relevante, mesmo porque as condições de assujeitamento político

\footnotetext{
${ }^{7}$ Neste mesmo número do Cadernos, há um texto sobre São Vicente, que é a primeira vila do Brasil, fundada por Martim Afonso, em 1532. O autor do artigo, E. Guimarães, analisa o que eu chamaria de processo de resignificação que a lei n4603, de 20 de março de 1965, do presidente militar H. Castelo Branco, produz ao denominar São Vicente como Célula Mater da Nacionalidade, concedendo-lhe a denominação/título de "Cidade Monumento da História Pátria”. São Vicente não foi a primeira cidade, era uma vila. A primeira cidade, que nunca foi vila, como dissemos, é São Salvador, e ser cidade naquele momento é fundamental pois desencadeou todo um processo de colonização, com governo, aparato e leis. Com a palavra do Rei. Isso faz parte do que eu disse, mais acima, sobre as diferentes histórias de uma história. Acontecimento e memória.
} 
e ideológico são aí determinantes, ou seja, fazem parte desse funcionamento. Esse funcionamento é observado como um efeito pragmático: esvaziamento de contradições, ilusão de não ambigüidade, de sentidos únicos e estáveis.

Em nossa análise, ao contrário, como veremos, procuraremos atentar às ambigüidades e contradições potenciais, à flutuação e indeterminação de conceitos, confrontando, uns ao outros, usos e sentidos diferentes que subsistem no mesmo momento, integrando na análise, como dizem Zancarini e Fournel (2008), a permanência das confusões ou das ambigüidades e a sutileza das fronteiras semânticas. Interessa-nos observar o funcionamento da "falha retornando pelo viés do absurdo" (M. Pêcheux, idem). Assim, podemos compreender melhor os processos de significação desencadeados por este Regimento na conjuntura histórica e política em que se apresenta como um discurso fundador, de um lado, ou um acontecimento discursivo, de outro. Como sabemos governam-se palavras, corpos e gestos em sociedade. Sentidos se traçam em trajetos sociais, percursos históricos. Com mais força ainda, se estamos em um momento em que se está organizando esta sociedade, pela expansão de um Estado. Ou seria criação de um Estado? Portugal - Brasil se juntam e se separam no batimento do processo de significação. Nada pode ser mais carregado de sentidos, de contradições, de equívocos. Vamos observar tanto a forma do regime político que se manifesta quanto a referência à forma de vida daquele que está se constituindo como "colono", como sujeito (cidadão? súdito?) de um país, de um Estado (ainda que submetido a) outro. E consideramos que, como dizem os autores (Zancarini e Fournel, idem), a ambigüidade não é indeterminação: ao contrário, ela traduz, de um lado, a complexidade da relação entre os indivíduos e a coletividade (eu diria: sociedade) - a dependência daqueles para esta mas também a inexistência desta sem aqueles - e, de outro, a modificação dos equilíbrios entre os diferentes parâmetros de análise política. Como são as formulações desse novo modo de significar e desse processo de constituição da forma sujeito histórica nesse espaço de significação que é o Brasil da colonização? Procuraremos vislumbrar processos e construção de sentidos e identidades em uma massa difusa de acontecimentos discursivos.

Não se analisam discursos sem pensar os sujeitos aí constituídos.

Por outro lado, a própria noção de "colonização" em seus modos de significar, não nos deixa alheios aos diferentes sentidos de Estado - ainda mais nascente e de certo modo "imposto" - que encontraremos: poder, cidade, governo, país, Estado, regime, território etc. O que implica em retrospectivamente pensar o próprio sentido de Língua de Estado, que estamos considerando. Trata-se da fala do Rei, trata-se da criação, para Tomé de Souza, de um discurso fundador, de um discurso para o/do Estado brasileiro. Marco do acontecimento discursivo da colonização. A distância entre "para o" e "do" Estado brasileiro é o grande desafio que temos de aceitar. Fazemos face a formações discursivas que regem o jogo de sentidos o tempo todo e que nos envolvem em filiações, em redes de sentidos diversas e, muitas vezes, concorrentes, conflitantes. Que fazem a falha retornar pelo viés do absurdo. Transferências, deslizamentos no interdiscurso. Efeitos de interdiscurso a se explicitar. Que memória aí significa? A do Estado português? A de um (outro) Estado (nascente)? As duas? A que migra de um para outro? Sentidos e sujeitos em movimento, em trânsito. Mas o Regimento é documento estabilizador: rege, administra, estabelece. Nomeia, ou seja, inscreve fato, acontecimento ou ser em um processo de significação. 
Já o acontecimento discursivo tem algo estabelecido: a partir daí, pela fundação de uma cidade fortaleza, temos o Estado, um governo no (do?) Brasil. Temos um governador geral Tomé de Souza e temos os seus administrados. Temos uma cidade, São Salvador, uma capital que traz, junto à sua fundação, um Estado português/brasileiro. Este Regimento é assim um acontecimento discursivo que institui uma cidade, um Estado, um governador, uma administração.

E se diz com o discurso que os Reis dizem. Vejamos um primeiro fragmento (Item): "Eu o Rei faço saber a vós Tome de Souza fidalgo de minha casa que Vendo Eu quanto serviço de Deus e meu é conservar e enobrecer as capitanias e povoações das terras do Brasil e dar ordem e maneira com que melhor e mais seguramente se possam ir povoando para exalçamento da nossa Santa Fe e proveito de meus reinos e senhorios e dos naturais deles ordenei ora de mandar nas ditas terras fazer uma fortaleza e povoação grande $\boldsymbol{e}$ forte em lugar conveniente para daí se dar favor e ajuda às outras povoações e se ministrar Justiça e prover nas coisas que cumprirem a meu serviço e aos negócios de minha fazenda e a bem das partes e por ser informado que a Bahia de Todos os Santos é o lugar mais conveniente da costa (...) e assento para isso vá uma armada com gente artilharia armas e munições e todo o mais que for necessário. E pela muita confiança que tenho em vós que em caso de tal qualidade e de tanta importância me sabereis servir com aquela fieldade e deligência que se para isso requer hei por bem de vós enviar por governador às ditas terras do Brasil no qual cargo e assim fazer da dita fortaleza a terra da Bahia vós haveis de ser capitão".

O primeiro objetivo, em nome do Rei e de Deus, exaltando a Fé e proveito do Reino, é a construção da fortaleza, da cidade (povoação grande) em lugar conveniente, e fazer Tomé de Souza governador. Instalar a segurança e a manutenção do espaço conquistado. Que continua em outro item: “Ao tempo que chegares à dita Bahia fareis saber por todas as vias que puderdes aos capitães das Capitanias da dita costa do Brasil de vossa chegada e eu lhes tenho escrito que tanto que o souberem vos enviem toda ajuda que puderem de gente e mantimentos e as mais coisas que na terra tiverem das que vos podem ser necessárias (...)”.

Aí está lavrada a fundação (de um espaço seguro, a cidade), a autoridade do rei, a transferência de poder a seu escolhido, o cargo de governador com seu poder arregimentador e a necessária obediência dos capitães. E, claro, a submissão dos que povoam estas terras. Observemos ainda, que, uma vez cumprido o gesto de fundação, daí para a frente o Rei fará um uso abusivo da palavra “dita”. Na Língua de Estado, o já nomeado, é o que já está assegurado na sua posse: está "dita".

Mas estejamos atentos ao fato de que o Estado aqui significa governo feito em nome do Rei de Portugal: fazer uma fortaleza e povoação grande e forte em lugar conveniente para daí se dar favor e ajuda às outras povoações e se ministrar Justiça e prover nas coisas que cumprirem a meu serviço e aos negócios de minha fazenda. O Estado aí não tem o sentido de Estado independente, nem mesmo individualizado pelo território: serviço de Deus e meu (o Rei) é conservar e enobrecer as capitanias e povoações das terras do Brasil. Refere, pois, às "terras" do Brasil que pertencem a Portugal. O Brasil, sem o Regimento, é apenas "terras". Essas mesmas que, ao longo de toda nossa história, são objeto de lutas incessantes (E. Orlandi, 1990). 
$\mathrm{Na}$ continuação de diferentes itens do Regimento, vemos se misturarem inextricavelmente posse, exercício de propriedade e religião, com os mesmos fins: o de submeter as gentes, a terra e o que nela houver . Na "dita" terra. Este "dita", repetido ao longo do texto, tem a força do pré-construído: produz o efeito do já nomeado, e, uma vez nomeado, como observamos, é propriedade. É território do Estado português, é terra governada. Submetida. Assim como seus habitantes, os povos que as habitam: a dita gente. Daí para as condições que são impostas aos habitantes é um passo:

"E tanto que a dita cerca for reparada e estiverdes provido do necessário e o tempo vos parecer disposto para isso praticareis com pessoas que o bem entendam a maneira que tereis para poder castigar os culpados o mais a vosso salvo e com menos risco da gente que puder ser e como assim tiverdes praticado o poreis em ordem destruindo-lhes as aldeias e povoações e matando e cativando aquela parte deles que vos parecer basta para seu castigo e exemplo de todos e dai em diante pedindo-vos paz lha concedais dando-lhe perdão e isso porem com eles ficarem reconhecendo sujeição e vassalagem $e$ com um encargo de darem em cada um ano mantimentos para a gente da povoação(...) por haver a vosso poder alguns dos principais que foram no dito alevantamento e estes mandareis por justiça enforcar nas aldeias onde eram principais".

É a paz da sujeição. Não se "fabrica" uma população de acordo com as posições e disposição destas. Mas de acordo com o plano administrativo de quem coloniza: já existem os parceiros, os inimigos, os que se aproveitam, os que se aproveitam em certas condições e os que serão ainda aproveitados. E, isto, claro, em nome de Deus e do Rei: "Somente pagarão o dizimo à Ordem de Nosso Senhor Jesus Cristo e com as condições e obrigações do foral dado às ditas terras e da minha ordenação no quarto livro título das sesmarias com condição que resida na povoação da dita Bahia (...)".

Governar, como significar (E. Orlandi, 1990, 1993), é estabelecer limites. E estes são nomeados no Regimento: "Porque minha tenção é que a dita povoação seja tal como atrás fica declarado hei por bem que ela tenha de termo e limite seis léguas para cada parte e sendo caso que para alguma parte não haja as ditas seis léguas por não haver tanta terra chegará o dito termo até onde chegarem as terras da dita capitania o qual termo mandareis demarcar de maneira que em todo o tempo se possa saber por onde parte". Administração do tempo e do espaço. E "dito" aí se apresenta para marcar que palavra de Rei tem força de realidade, de reconhecimento e de posse. Os limites são explicitados, mas/portanto o resto está no "dito".

É no "dito" que, muitas vezes, os sentidos fogem ao controle. As "sutilezas das fronteiras" em que a "ambiguidade dos sentidos não é indeterminação mas traduz a complexidade da relação" entre indivíduos e sociedade. São sujeitos sujeitos ao equívoco, prontos "para que a falha retorne pelo viés do absurdo". Que Estado é este? O que está posto neste "dito"? É a história em seu pleno movimento. Histórias.

Administra-se também a posse da terra (e as águas) e seu uso: "As águas das ribeiras que estiverem no dito termo em que houver disposição para se poderem fazer engenhos daçúcares ou doutras quaisquer coisas dareis de sesmarias livremente sem foro algum e as que deres para engenhos daçúcares será a pessoa que tenha possibilidade para os

8 "Dita" cerca é o mesmo que "fortaleza" e, por extensão, pertencente ao governo de São Salvador. 
poderem fazer dentro no tempo que lhe limitardes". Tudo bem estabelecido pela palavra do Rei. A produção de açúcar já está prevista e organizada.

Quanto à sobrevivência da população, não só se assegura a defesa dos espaços, mas também "que nas ditas Vilas e povoações se faça em um dia da semana ou mais que se vos parecerem necessários feira a que nos gentios possam vir vender o que tiverem e quiserem comprar o que houverem mister e assim ordenareis que os cristãos não vão às aldeias dos gentios a tratar com eles salvo os senhorios e gentes dos engenhos(...) e que será melhor ordenar-se que uma só pessoa em cada engenho o faça e assim se fará". Ou seja, determina-se quem fará e como será o contato com os "gentios" (não qualquer cristão mas pessoa do engenho ou senhorio), mesmo se estes são necessários para produzir os alimentos. Do mesmo modo, se delibera sobre o direito de ir e vir: "Eu sou informado que nas ditas terras e povoações do Brasil há algumas pessoas que têm navios caravelões e andam neles de umas capitanias para outras e que por todas as vias e maneiras que podem salteiam e roubam os gentios que estão em paz e enganosamente os metem nos ditos navios e os levam a vender a seus inimigos e a outras partes e que por isso os ditos gentios se alevantam e fazem guerra aos cristãos (...) hei por bem que daqui em diante pessoa alguma de qualquer qualidade e condição que seja não vá saltear nem fazer guerra (...) sem vossa licença ou do capitão da capitania (...)".

Com essas palavras o rei divide a população, nomeia os inimigos, organiza as relações entre as gentes das povoações, administra o direito de ir e vir, como dissemos acima. E dá autoridade a capitães e a Tomé de Souza.

Também o comércio merece atenção: "os que forem a tratar e negociar suas fazendas pelo mar de umas capitanias(...) para fazer as diligências que lhe em seu regimento mando acerca das mercadorias que se nos ditos navios hão de carregar (...)".

A distribuição de armas pela população e as que são necessárias para a defesa das terras é cuidadosamente administrada. Não só das terras dos capitães e senhorios dos engenhos mas também das terras do dito Brasil face a corsários que se aproximam pelo mar. O Regimento é um instrumento de poder que cuida em detalhe do território, do que existe nele, da sua posse, e da divisão das características, gentes, direitos dos que o povoam e de sua relação com as terras, sem esquecer de seus bens, como o pau Brasil: "Porque por bem do farol dado às capitanias das ditas terras pertencem a mim todo o pau do dito Brasil e pessoa alguma pode nele tratar (...)".

O texto todo é atravessado pela necessidade de colocar ordem na sociedade nascente. Separar gentios e cristãos e determinar as posses que cada um pode ter. Dividir, mesmo no espaço: "será grande inconveniente os gentios que se tornaram cristãos andarem misturados (...) com os outros".

Mas podemos dizer que, passando por estes detalhes do Regimento, há algo maior que lhe dá sentido. Ter uma cidade grande, uma capital, face às miríades de povoações, é fundamental para a colonização, para representar a organização do território, dos que o povoam, das práticas que nessas terras se dão. O primeiro gesto político-administrativo da colonização: "ordenei(...) de fazer uma fortaleza grande e forte em um lugar conveniente". Isto é São Salvador. Símbolo do poder, da segurança, da defesa do território e das gentes (mais seguramente possa ser povoado) e de sua posse e organização.

A segurança já é então uma questão de base e ter uma cidade grande, uma capital segura é parte da colonização que assim se estabelece. 


\section{CONCLUINDO}

Pensando a formação do Brasil a partir deste Regimento que tem em primeira instância a formulação do Rei (ordeno) sobre a cidade de São Salvador - uma fortaleza em lugar conveniente - podemos avaliar os efeitos de sentidos do que é uma Cidade no processo de colonização9. Cidade que vai, como Capital, significar a administração de uma unidade territorial, uma unidade administrativa, um governo. O sentido da dominação da territorialidade instala-se pelo urbano. Centralizador. O urbano-capital. Nele se instala o princípio de organização das terras, da economia, da população, do comércio, do direito de ir e vir. Fortaleza, a cidade simboliza o poder pela força, face aos de fora e para os de dentro do território, instala-se já o estado de guerra sob o qual vai se delinear o processo colonizador. Em que os padres que virão, com as técnicas da catequese, são tão violentos quanto os sesmeiros (E. Orlandi, 1990).

Em minhas análises com o discurso missionário, o da pacificação, o da inscrição da língua nos relatos de missionários e viajantes (E. Orlandi, idem) aprendi que há três formações discursivas articuladas - política, religiosa e científica - que resultam no discurso sobre o Brasil, que é o discurso da dominação do país europeu. Essa articulação é característica da colonização. Nessa relação de sentidos que se produz é a dominação da Europa sobre a América que se "diz", significa.

Há uma articulação numa produção de efeitos de sentidos que resulta: colonização, poder europeu. Se há uma aliança entre o político, o religioso e o científico que resulta em dominação do Rei e de Deus, por outro lado, há um recobrimento da ciência sobre a tecnologia que recobre um desígnio administrativo ${ }^{10}$.

Essa forma de conhecimento sobre o Brasil - coisas a saber - que vemos não só nos relatos mas também presente no Regimento, produz uma tecnologia que por sua vez produz instrumentos administrativos que servem a uma forma de governo - em nosso caso o que rege o poder da colonização: normas e poderes constituídos e distribuídos pelas "terras do Brasil".

Não são, pois, modos de dizer jogados ao ar. A religião, por sua vez, é base de constituição de uma certa tecnologia - a catequese - sustentada por uma forma de conhecimento que, por essa tecnologia, vai administrar o Novo Mundo (a catequese), onde Deus e Rei estão juntos. Não há ambigüidade, há sobreposição, um efeito articulado entre eles.

Se olharmos de uma perspectiva epistemológica, a escrita do Regimento não se volta tanto para a notícia da descoberta, já que seu fim jurídico-político é muito mais enfatizado,

\footnotetext{
${ }^{9}$ Quero aqui lembrar o que diz M. de Nantes (1706): “assim, não sabiam o que era beleza, magnificência, grandeza, nem mesmo quantidade senão pela vista". Este era o "alcance do seu espírito". A sua falta de racionalidade os impedia de admirar as grandezas da civilização ocidental "não podendo elevar-se ao seu conhecimento pela beleza das coisas sensíveis que não conheciam. Eis porque os mandava à Bahia (São Salvador)". É o que analiso em Terra à Vista (1990). Chamo a atenção para a relação de Cidade com magnificência e civilização ocidental. ${ }^{10} \mathrm{Cf}$ em M. Pêcheux (1990) p.32: "a homogeneidade lógica que é atravessada por uma série de equívocos que "cobrem" ao mesmo tempo, como um patchwork heteróclito, o domínio das ciências exatas, o das tecnologias e o das administrações."

${ }^{10} \mathrm{Cf}$ em M. Pêcheux (1990) p.32: "a homogeneidade lógica que é atravessada por uma série de equívocos que "cobrem" ao mesmo tempo, como um patchwork heteróclito, o domínio das ciências exatas, o das tecnologias e o das administrações."
} 
e, desse ponto de vista, pode servir só de forma marginal à geografia e à cartografia. Mais do que fazer circular o que produz como conhecimento das terras e da população, de forma sistemática e abrangente, para fora, este documento se volta para a circulação e o saber para dentro, nos domínios do território cartografado. Se endereça menos a um conhecimento que liga universalmente a geografia e a política do que é um instrumento de poder dirigido e com função pragmática bastante acentuada.

O Regimento funciona como um documento mas está sobretudo permeado de conhecimentos que o sustentam como uma peça administrativa de poder que funciona na jurisdição. Instrumento legal do Rei que, na medida em que regula as relações dos gentios e os espaços em que vivem, ou mesmo seu trânsito, precede a via da prática de uma tecnologia que se pressente: a que serve e se vale de Deus, a tecnologia da catequese; que administrará a relação com a população indígena, espraiando, no entanto, seus efeitos sobre todo o território ocupado.

O Regimento é antes de tudo o instrumento régio, legal, que funda uma cidade, base da colonização. É peça da administração jurídico-política. A catequese, que virá, é a forma por excelência da tecnologia da colonização. A cidade é o espaço material institucionalizado em que isto se instala e que daí se irradia. Nos aldeamentos, reduções.

Este Regimento tem elementos abundantes para uma análise que se estenderia sobre muitos fatos de linguagem para a compreensão desse processo discursivo que toca a questão da colonização, a formação do Brasil e o lugar nuclear da fundação de uma cidade, nos muitos sentidos que aí estão produzidos e as diferentes direções que tomam. As histórias do Brasil. Ficamos, no entanto, por uma questão prática, neste recorte que nos mostra, que torna visíveis alguns desses sentidos onde a questão urbana aparece declinada de maneira diversa da que tínhamos analisado até agora: a cidade vinculada ao acontecimento da colonização.

\section{REFERÊNCIAS BIBLIOGRÁFICAS}

ALVEZ FILHO, I. (1999). Brasil, 500 anos em documentos, Rio de Janeiro: Mauad.

DURKHEIM, E. (2002). Lições de sociologia: a moral, o direito, o Estado, São Paulo: Martins Fontes.

EDELWEISS, F. “As missões dos Quiriris e de outros tapuias ao tempo de Frei Martinho de Nantes”, Revista Brasileira de História. Xerox.

MAQUIAVEL, N. (1969). O Príncipe, Rio de Janeiro: Civilização Brasileira.

NANTES, M. (1952). Rélation succinte et sincère. Paris, 1706; Ed. fac-sim.,Salvador, Bahia. (trad. Brasileira: Editora Nacional, S.P., 1979).

ORLANDI, E. (1990). Terra à Vista, São Paulo: Ed. Unicamp/Cortez, 1990.

ORLANDI, E. P. (2011). "Os sentidos de uma estátua: Fernão Dias, individuação e identidade pousoalegrense", in Discurso, espaço, memória - caminhos da identidade no sul de Minas, Campinas: RG editora.

PÊCHEUX, M. (2011). Análise de Discurso - M. Pêcheux - textos escolhidos por E. P. Orlandi, Campinas: Pontes Eds, 2011. 
ZANCARINI, J. C.; FOURNEL, J-L; DESCENDRE, R. (2008). Estudos sobre a língua política, Campinas: Ed.Unemat/RG.

WEBER, M. (1991). Economia e Sociedade. Brasília: editora UNB. 